\title{
Evidence-Based Synopsis of Interventions, a New Tool in Primate Conservation and Research
}

\author{
S. O. Petrovan ${ }^{1}$ - J. Junker ${ }^{2}$ - C. F. R. Wordley ${ }^{1}$ • \\ H. S. Kühl ${ }^{2}$ L. Orth ${ }^{2}$ - R. K. Smith ${ }^{1}$. \\ W. J. Sutherland ${ }^{1}$
}

Received: 10 November 2017 / Accepted: 30 December 2017 / Published online: 23 January 2018

(C) Springer Science+Business Media, LLC, part of Springer Nature 2018

Biodiversity conservation is often described as a crisis discipline, with conservationists rushing from one emergency to the next. This frequently leaves limited resources available to evaluate the effectiveness of the conservation interventions that have been implemented. Furthermore, for those seeking out scientific evidence for conservation decisions, much is locked behind subscription-only access or hidden in jargon-heavy literature. Assessing the effectiveness of conservation interventions, and making the results readily available to practitioners, could transform conservation efforts.

Initiatives such as the Cochrane Collaboration (http://www.cochrane.org) in medicine have saved and improved lives across the world, by collating and reviewing the evidence on scientific trials of medical treatments. For example, cot deaths dropped dramatically once data were collated and analyzed, reversing the advice provided for decades on sleeping positions for babies (Gilbert et al. 2005). In conservation, reed bed burning and bat gantries are notable examples of where the accepted approach was ineffective or even actively harmful for the species involved (Berthinussen and Altringham 2012; Ditlhogo et al. 1992). The Conservation Evidence project (www.conservationevidence.com) echoes the Cochrane Collaboration by collating information on how well conservation interventions (any action you might do to manage, protect, enhance, or restore biodiversity or ecosystem services) have worked, providing a free, authoritative, and user-friendly resource to facilitate effective

S. O. Petrovan and J. Junker are joint first authors.

Handling Editor: Joanna M. Setchell

S. O. Petrovan

sop21@cam.ac.uk

1 Department of Zoology, University of Cambridge, Cambridge CB2 3QZ, UK

2 Department of Primatology, Max Planck Institute for Evolutionary Anthropology,

D-04103 Leipzig, Germany 
decision making. The project is working to collect data for all interventions, for all species groups and habitats, everywhere in the world: a daunting task, but one already well underway, with more than 1500 interventions assessed so far using more than 5400 studies.

The latest synthesis work from the Conservation Evidence project focuses on global primate conservation. The Primate Synopsis (Junker et al. 2017) is the result of a collaboration with researchers at the Max Planck Institute for Evolutionary Anthropology, Germany, to produce a comprehensive database of the effectiveness of conservation interventions for all nonhuman primate species. An international advisory board of 23 primate experts assisted in producing a comprehensive list of interventions, which we categorized according to the IUCN threat category they addressed. We systematically searched 146 general conservation scientific journals and 18 specialist primate journals and newsletters for studies testing primate conservation interventions, complemented with keyword searches of PLoS journals. This identified 80 relevant papers for 162 interventions, gathered in a synopsis consisting of 13 chapters tackling topics from local livelihood projects to roads. We did not separate planned from opportunistic studies, as many interventions could be either, depending on the circumstances; for example, some programs may deliberately seek out abandoned, injured, or illegally kept primates and rehabilitate them for release, whereas others might do this only opportunistically. However, we had to exclude several of the more opportunistic studies, as they did not provide any quantitative data on the effect of interventions while other studies did not undertake any postimplementation monitoring of populations or individuals.

We summarized each paper testing an intervention, e.g., "Install rope canopy bridges for primates," in a short, standardized paragraph in plain English, highlighting the study design and main findings. Key messages provide an overview of how effective (or otherwise) each intervention has been. Finally, using the Delphi technique (Mukherjee et al. 2015), an expert panel assessed each intervention by scoring the certainty of the available evidence, the apparent effectiveness, and any harms. The panel combines primatologists from academia and international nongovernmental organizations. The resulting scores categorize the effectiveness of each intervention as, e.g., "beneficial," a "trade-off between benefits and harms," or "likely to be ineffective or harmful."

The Primate Synopsis can be accessed in three ways. The first is a PDF that summarizes the evidence available for every intervention. This allows the synopsis to be downloaded - for free - and read in areas with limited or no internet, but does not include the expert assessment. The second is a chapter in What Works in Conservation, a book produced annually that summarizes all the synopses with the expert assessment. It is available as a free PDF or a physical book. The third, most powerful, option is part of the free, searchable online database. This allows users to find relevant results instantly; to order interventions by the number of studies, or by effectiveness category, or to refine the search by country; and to check information in other synopses (e.g., education programs that apply across taxa).

Around $60 \%$ of primate species are threatened with extinction and three-quarters are declining (Estrada et al. 2017). Conserving them will require effective actions spanning multiple strategies, from habitat protection to preventing disease transmission. However, despite their high profile, remarkably little tested evidence is available on the best ways to conserve primates, especially for small, nocturnal species and primates in 
South America and Asia (Junker et al. 2017). For many (59\%) of the interventions identified by the advisory board, we found no evidence during the journal searches as to whether they worked or not; i.e., no studies testing the intervention were found. Although some of this information might exist in gray literature reports, it is disparate and extremely difficult to find, and therefore not available for the wider community to use to inform their management actions.

Primate conservationists can use Conservation Evidence in several ways. First, they can seek evidence when deciding which conservation actions to implement. Reading about what other studies have found may help decide on the option that is most likely to be effective, e.g., whether to put effort into training antipoaching patrols, involving local communities in conservation, or implementing a community-based hunting ban. Owing to the importance of first examining the evidence, several primate conservation funders, such as the People's Trust for Endangered Species and Whitley Fund for Nature, are encouraging grant applicants to seek evidence from the Conservation Evidence project to assess the likelihood of success of a project. Of course, evidence should be used along with knowledge of the local situation, and practical considerations such as cost and species applicability, in order to make decisions that have the highest likelihood of being effective (Fig. 1).

Second, primate conservationists could help fill the substantial knowledge gaps highlighted by the Primate Synopsis. Does playing primate alarm calls in farmland deter primates from raiding crops? Can green bridges reduce primate deaths on roads? These are some of the questions for which we found no studies during our searches that
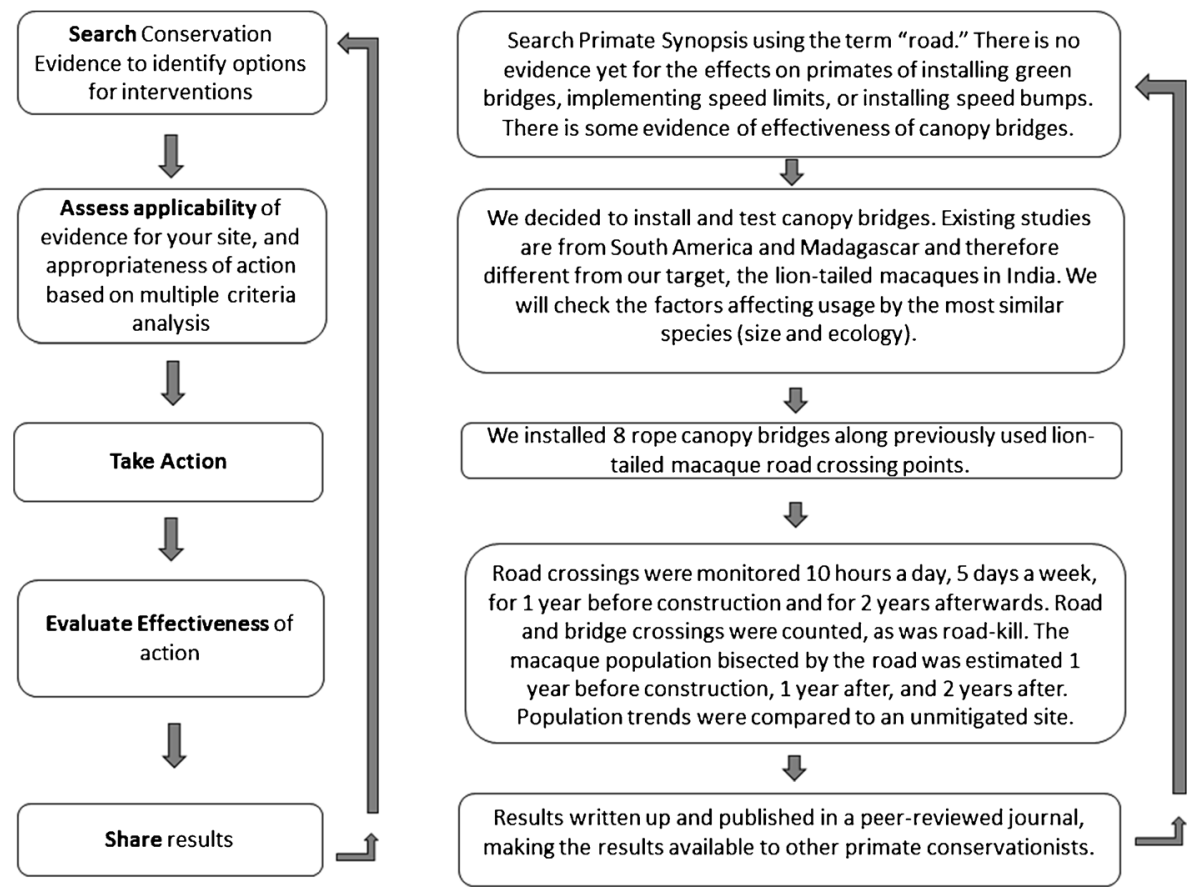

Fig. 1 Illustration of how using and generating evidence produces a positive feedback loop — in general, left, and using a hypothetical example - trying to reduce road deaths and population-level declines in lion-tailed macaques (Macaca silenus) in India, right. 
tested whether the interventions worked or not. Evaluating these interventions and publishing the results would help other conservationists make better-informed decisions for primates. Conservation Evidence also has a no-fee journal in which practitioners can share their findings with the global community.

Third, the Primate Synopsis found that conservation actions were frequently implemented concurrently, making it difficult to assess the efficacy of any one action. This is understandable, as most of these projects were designed as conservation projects rather than research projects. Where possible, when planning projects, having a testing phase during which one strategy at a time is implemented, even if several interventions will eventually be implemented together, would help conservationists understand what is working, when, and why. Where evidence exists for an intervention, testing it for a different species or in a different context would improve understanding of how reliably it works. The free PRISM Toolkit (http://www.conservationevaluation.org) can help practitioners design adequate evaluation of conservation projects.

Finally, spread the word about the Conservation Evidence project. Conservationists across the world can access, use, and add to this resource, making it a valuable, living database. If you have any suggestions for improvements for the synopsis updates, for example, studies we may have missed, please contact us at info@conservationevidence.com. Using and producing the best possible science is key to ensuring the next generation sees a world that sustains thriving populations of primates. Collectively, we can all learn to do conservation better.

Acknowledgments We are grateful to the funders of the Primate Synopsis work, Robert Bosch Stiftung at Max Planck Institute for Evolutionary Anthropology in Germany and Arcadia for the Conservation Evidence work at the University of Cambridge.

\section{References}

Berthinussen, A., \& Altringham, J. (2012). Do bat gantries and underpasses help bats cross roads safely? PLoS One, 7(6), e38775. https://doi.org/10.1371/journal.pone.0038775.

Ditlhogo, M. K. M., James, R., Laurence, B. R., \& Sutherland, W. J. (1992). The effect of conservation management of reed beds. I. The invertebrates. Journal of Applied Ecology, 29, 265-276. https://doi.org/10.2307/2404495.

Estrada, A., Garber, P. A., Rylands, A. B., Roos, C., Fernandez-Duque, E., et al (2017). Impending extinction crisis of the world's primates: Why primates matter. Science Advances, 3(1), e1600946. https://doi.org/10.1126/sciadv.1600946.

Gilbert, R., Salanti, G., Harden, M., \& See, S. (2005). Infant sleeping position and the sudden infant death syndrome: Systematic review of observational studies and historical review of recommendations from 1940 to 2002. International Journal of Epidemiology, 34, 874-887. https://doi.org/10.1093/ije/dyi088.

Junker, J., Kühl, H. S., Orth, L., Smith, R. K., Petrovan, S. O., \& Sutherland, W. J. (2017). Primate conservation: Global evidence for the effects of interventions. Cambridge: University of Cambridge.

Mukherjee, N., Huge, J., Sutherland, W. J., McNeill, J., Van Opstal, M., et al (2015). The Delphi technique in ecology and biological conservation: Applications and guidelines. Methods in Ecology and Evolution, 6, 1097-1109. https://doi.org/10.1111/2041-210X.12387. 